\title{
Stability of stratification and its effect on the accumulation of ferrous iron in meromictic Lake Towuti
}

\author{
TONGYAO PU ${ }^{1}$, SEAN CROWE ${ }^{2,3}$ AND SERGEI KATSEV ${ }^{1}$ \\ ${ }^{1}$ University of Minnesota Duluth \\ ${ }^{2}$ University of Hong Kong \\ ${ }^{3}$ University of British Columbia \\ Presenting Author: pu000031@umn.edu
}

The oceans of the Early Earth are thought to have been variably ferruginous or euxinic, but the conditions that regulate the concentrations of dissolved iron or hydrogen sulfide are poorly understood. Lake Towuti (Indonesia) is a $200 \mathrm{~m}$ deep tropical lake that is presently stratified with ferruginous conditions developed below the $125 \mathrm{~m}$ deep chemocline. Sediment record, however, documents millennial-scale transitions in the lake's redox regime [1], and its morphological characteristics allow for the possibility of episodic mixing on shorter, decadal time scales. This variability provides an opportunity to probe the genesis of ferruginous conditions in a modern stratified environment with a well-resolved sediment record. We investigated the stability of stratification in Lake Towuti using a hydrodynamic $k-\varepsilon$ model, Simstrat V2.0, under a range of both modern and past climate conditions. The obtained rates of vertical mixing were further used in a reactive-transport model to reproduce the chemical dynamics and identify the factors that regulate the accumulations of ferrous iron or hydrogen sulfide. We find that the stratification of modern Lake Towuti can break down under strong wind, or in response to reduced solar insolation or decreased air temperature. Such episodic mixing would ventilate the deep waters and reset the accumulation of ferrous iron, which would then take several decades to resume. Over longer time scales mixing is expected to occur under a cooler or dryer climate, with lower water levels. Transient conditions can result in mixed ferruginous-euxinic states where dissolved iron and hydrogen sulfide coexist at low concentrations. The eventually achieved concentrations of ferrous iron may vary by as much as several orders of magnitude, being sensitive to the rates of vertical mixing and dependent on the pathways of iron delivery and rates of chemical recycling at the chemocline. The results indicate that the chemical balance in a ferruginous stratified environment may strongly depend on the physical setting, hinting at a potentially similar variability in the water chemistries in early marine environments.

[1] Russell et al. (2020), Palaeogeography, Palaeoclimatology, Palaeoecology, 556, 109905. 